\title{
Journalists at Digital Television Newsrooms in Britain and Spain: workflow and multi-skilling in a competitive environment
}

\author{
JOSÉ ALBERTO GARCÍA AVILÉS and BIENVENIDO LEÓN University of Navarra, \\ Spain
}

KAREN SANDERS and JACKIE HARRISON University of Sheffield, UK

\begin{abstract}
This paper explores the impact of new technology on journalists' attitudes and practice in distinctive national and organisational contexts, deriving evidence from observational and interview research conducted in six digital newsrooms selected to provide comparative settings in Britain (BSkyB, Independent Television News [ITN] and the British Broadcasting Corporation [BBC]) and Spain (Telecinco, Antena 3 and Telemadrid). The study explores the perceived rationale for digitisation, its impact on workflow and multi-skilling, and the changes it has generated in journalistic practice. The influence of digitisation is shown to be significant in both countries. The evidence indicates, however, that in terms of attitudes, practice and technological provision, the relatively younger, smaller Spanish newsrooms reflect digitised journalism more fully. Nevertheless, journalists in both countries expressed concerns about the attrition of core journalistic values, as journalists become increasingly computer-bound "mouse monkeys" required to trade accuracy for immediacy in the speeded-up world of digital and 24-hour news.
\end{abstract}

KeY Words: Television Newsrooms, Digital Television News, Spanish Television News, British Television News, Journalistic Practice, News Technology.

\section{Technology and Journalism Practice}

Television news, by its nature, faces an ongoing process of change. Technological, market and global developments have influenced the way television news is gathered, produced and presented. The pace of change has accelerated over the last ten years reflecting the impact of political and economic factors (a liberalised economic environment and deregulation), technological changes (digitisation of news input and output and the growing use of live transmissions) and global developments (which show an increasing connectedness of events around the world). As Schudson argues, news production is under constraints imposed by organisations, despite the private intentions of individual actors, and by the practices acquired by journalists in their daily routines (Schudson, 2000, p. 193). Cottle (1995) takes a step further, suggesting that news values are increasingly tied to particular economic demands made upon news executives, while journalistic evaluation of the newsworthiness of stories is adapted to fit particular programme needs. Ursell (2003) argues that a process of dumbing down of professional practice is occurring in television newsrooms. Such developments raise concerns about the evolution of journalistic practice in the contemporary digital television news environment.

Discussion of the impact of new technology on journalists' practice is as old as journalism itself (Schudson, 1995; Winston, 1998). The railway, the telegraph and later radio, television and the internet have all played their part in the development of journalism. It is hard to disagree with Pavlik's assertion that "the way journalists work has always been influenced, constrained and structured by technology" 
(1999, p. 54). This commonly accepted starting point begs two further questions. First, how precisely does technology influence journalists' work in Spain compared with Britain; second, is there anything distinctive about current technological change which is making a qualitative difference to journalism practice and output?

Cottle (1999) introduces his study of a British Broadcasting Corporation (BBC) regional newscentre by pointing to the normative professional concerns about the impact of new technology which have largely focused on the belief that analytical depth is being traded for immediacy. His premise, shared by this study, is that technology is a factor in the changing news production environment (1999, p. 23). However, as his work also points out, discussion of technology's role has been largely atheoretical and based on slender empirical evidence. Firmer theoretical foundations and a larger body of empirical studies are, we agree, necessary "to improve our understanding of the complex interactions between changing news technologies and journalist practices" (1999, p. 26).

A number of theoretical approaches to technology's role can be identified in the literature. Marjoribanks (2000) examines the relationship between the introduction of technology and workplace reorganisation in the newspaper industry, taking News Corporation as a case study. His comparative study of the newspapers of this group in the United Kingdom, the United States and Australia concludes that the introduction of computerised systems brought about a significant modification of the journalistic skills required. He analyses various theoretical approaches, including technological determinism, labour process theory, the institutional social choice model, the relational model of workplace organisation and, finally, the modified relational model.

Pavlik (1999) takes a Panglossian view of technology's effects. Using the reporting of the Oklahoma bomb in 1995 as an example, he outlines the advantages that the introduction of new technology have brought to the telling of the story so that it is "put in better context, accuracy is increased and lead, sources and story angles are more quickly identified" (1999, p. 55).
On the other hand, far from enhancing the journalist's role, new technology has also been seen as a management tool used in part to deskill the workforce and play its part in the economic and social battles fought between management and news workers (Hardt, 1990). MacGregor (1997) recognises too the wider forces that have come to bear upon news production. However, he explores how new technology contributes to the shaping of the message, often in ways that lend weight to journalists' concerns about the sacrifice of depth for immediacy.

The implicit McLuhanism found in MacGregor (that the "medium is the message") is turned on its head by Winston's (1998) historical exploration of the cultural grounds that play as significant a role in shaping new technology as new technology does in shaping culture. This view finds some empirical support in Cottle's work (1993). However, his later study of a BBC newscentre (1999) provides evidence for a more nuanced view of the interaction of new technology with journalistic practice and output. On the one hand, he finds that journalists are more computer-bound and pressurised by multiskilling and multimedia working practices, lending support to Hardt's (1990) position and to Bromley's (1997) critique of the deleterious impact of news technology on journalists' working practices. Cottle also discovers, however, that journalists welcome increased control over work processes and the news product; the new technology of news production, far from determining content, is placed at the service of conventional forms of news so that, he concludes, "despite the professional turmoil generated by the pressures and new working practices of multi-skilled, multi-media production, the news appears pretty much business as usual" (1999, p. 41).

Some journalists, academics and media analysts see technological change as a negative development that affects news content and the journalist's ability to undertake his or her core function, namely, to investigate. John Tusa recalled in his 1994 James Cameron Memorial Lecture that a reporter had recently commented to him that "we're not correspondents any more. We're scarcely even reporters. We have 
become re-processors. There is no time for digging up the news" (Tusa, 1994, p. 4, cited in Harrison, 2000, p.120). The advent of the "mouse monkey"-the computer-bound journalist-has taken the ability to reprocess and repackage news to new technological heights, allowing some multi-skilled broadcast journalists to take agency and location feeds and turn them into a variety of packages to meet different programme editors' visions of their programme (MacGregor, 1997)

The growth of satellite, cable and digital channels has led to an increase in news programmes and outlets. In Britain there has been an eight-fold increase in the supply of television news in the last decade, with about 243 hours a week available to viewers in 2002 (BBC, 2002), compared with about 30 hours in 1989. The increase in the amount of news on television, coupled with the advent of 24-hour news programming, has made the immediate a key feature of everyday television journalism. Reporters have the role of witness, writes Peters, "as an observer or source possessing privileged (raw, authentic) proximity to facts" (2001, p. 709).

The culture of broadcast journalism has always placed strong emphasis on deadlines and timing precision within news programmes during their broadcast. Schlesinger (1987, p. 84) identifies this as "a stop-watch culture". In those newsrooms dealing with appointment programmes, there is a period of calm activity that gradually builds into more frenzied activity the closer the deadline gets and as time runs out. In contrast, 24-hour newsrooms must exist in a constant broadcasting state, where time has always run out and everything must be broadcast immediately (Sanders and Bale, 2000). The sense of rush and shortage of time is becoming an important element of newsroom culture, where to be obsessed by time is a constant element of the news day with no sense of reprieve. In this context, the coverage of the events of September 11, 2001 and of the war in Iraq were, in many different ways, two of the greatest challenges for any television news organisation. They were also unprecedented tests of digital news production systems.

Broadcasters everywhere are gradually im- plementing digital newsrooms. Finnish public service broadcasting (YLE) introduced a digital, automatised system in 1996. In Spain, the commercial network Telecinco was the first to launch a fully digital news operation in August 1998, and the commercial network Antena 3 followed in September 1999. The BBC introduced its digital 24-hour news channel in November 1997. Sky launched digital services in 1998 and Independent Television News (ITN) followed in 2000. Other broadcasters, such as Italy's Mediaset and RAI, and France's TF1, also went digital throughout 2000. In the USA, a number of local stations, as well as the main 24-hour news channels (CNN, MSNBC and Fox News) have implemented digital newsrooms since 2001. However, none of the main networks (NBC, $A B C$ and $C B S$ ) has yet converted to digital.

Some researchers have examined this changing working environment in both Britain and Spain. In addition to Cottle's (1999) pioneering study, Ursell (2001) examined journalistic practices at three British television newsrooms (British Broadcasting Corporation, Independent Television News and Yorkshire Television). All of them are news broadcasters, but the markets where they operate, the scale of their production systems and the levels of technological development are different. Ursell (2001, p. 194) stated that "demand for and pressures on journalistic staff have increased in all three". In a more recent article, she found that employment and working conditions in the production of journalism-based television programmes in Britain have worsened, with negative consequences for the quality of the output (Ursell, 2003).

The development of digital newsrooms by Spanish broadcasters has been documented by Bandrés et al. (2000). These authors examine how journalists have adapted to new ways of accessing, editing and producing information, and they argue this process could be regarded as a "revolution" similar to the use of communication satellites or the replacement of film by videotape (Bandrés et al., 2000, pp. 22-26). More recently, in their analysis of the implementation of the digital system at two commercial Spanish television newsrooms, García 
Avilés and León (2002, p. 367) argued that the "new system has enabled journalists to take direct control over the process of producing a news package and it has increased their responsibility". Similarly, these authors discuss the trend in multi-skilling and the growth in the work load faced by television journalists.

Taking into account these theoretical considerations, and the issues they raise in relation to the changing nature of journalistic practice, this article examines professional attitudes and practices in several digital television newsrooms. We have focused on Britain and Spain, two countries where broadcasters have been among the first worldwide to introduce a digital newsroom. In Britain research was conducted in a British public service organisation, the British Broadcasting Corporation (BBC) and the digital newsrooms of commercial broadcasters BSkyB and Independent Television News. The latter provides news programmes for Channels 3,4 and 5 of the independent television network (ITV). In Britain, news professionals from Sky News, ITN's Channel 3 and News-24 newsrooms and both BBC World and News-24 newsrooms were interviewed: in Spain, research focused on the commercial channels Telecinco and Antena 3 and the Spanish public regional channel Telemadrid. Interviews with journalists were conducted at each of the three digital newsrooms. ${ }^{1}$

The symmetry in the choice of commercial and public channels in two different national contexts was deliberate. Part of the underlying theoretical rationale for this research was to explore assumptions about journalists' perceptions of the adoption of new technology in distinct national and organisational contexts. Comparative work is difficult (Blumler and Gurevitch, 1995), which is perhaps why comparative media research is relatively thin on the ground (Blumler et al., 1992). It requires deep knowledge of the worlds being examined as well as methods that allow meaningful equivalences to be established which, at the same time, do not neglect the wealth of different meanings that exist in diverse cultural contexts. Indeed, although comparative research has grown in frequency and scope in recent years, it remains an extendable frontier (see Blumler et al., 1992).
In comparative research the key is, first, to find objects that can be compared, and whose comparison can yield useful insights into the field being examined, and second, to establish mechanisms to ensure the reliability of the comparisons being made. Our study focuses on the perceptions and practices of news directors and journalists working in broadcast newsrooms in which digital technology has replaced analogue equipment.

\section{Implementing Digital Newsrooms in Britain and Spain: the context}

In Britain, the first 24-hour news channel was launched by BSkyB in 1989. By capitalising on technological development, it was able to make its primary commitment the speed of delivery of stories, since at that time the BBC and ITN could only provide appointment news programmes on the terrestrial channels. Sky News's 24-hour rolling news format was modelled on the style of CNN, bringing a new style of news delivery to British television. The 24hour news format was eventually followed by the BBC, which launched BBC News-24, and by ITN, which launched its own 24-hour news channel in 2000. To date, the BBC has taken an aggressive approach towards its role in the digital television and news environment. By 2003 the BBC's News-24 had become a successful competitor to both Sky News and ITN's 24-hour news.

By contrast, the digital fortunes of the ITV system have been more mixed, with major problems prompted by the fall in advertising income and the eventual collapse of ITV Digital in March 2002. ITV's news supplier, ITN, has faced unprecedented competition. When it was first formed in 1955, ITN was nominated the sole news provider for the independent television sector (ITV) and was owned by all the regional television companies. In 1993 ITN became independent of ITV when a consortium of broadcasters, acting as shareholders rather than sponsors, assumed control. Independent Television News now competes with commercial companies such as Sky News for the news contract from ITV. Although ITN won the contract for news provision to the ITV sector in 
2002, it was obliged to reduce its bid to $£ 36$ million, creating a deficit of $£ 10$ million compared with 2001. Independent Television News's 24-hour news channel, launched on 1 August 2000, offered a similar format to Sky News and BBC News-24, with a round-up of news every 15 minutes and an interactive service. The ITN News Channel was launched as a joint venture with cable-broadband company NTL, but remained a loss-making company. ITV bought out the majority share in June 2002 and the ITN News Channel has been relaunched as the ITV News Channel. This will lead to greater integration between ITV's main terrestrial news programmes (shown on Channels 3, 4 and 5) and the 24-hour channel shown only on digital television. This is likely to increase pressures on ITN journalists to serve a larger number of outlets and to engage more in 24-hour news delivery. It has already triggered redundancies (Byrne, 2002). The budgets for the three 24-hour news channels illustrate the scale of ITN's difficulties. While BBC News-24 has a budget of around $£ 40$ million and Sky News approximately $£ 30$ million, ITN invests only $£ 10$ million in its news channel (Hodgson, 2002).

At the BBC and at Sky News particularly, the process of digitisation has been very uneven. Digital technology was first introduced at BBC Millbank, the Political Unit, in 1992 to 1993. Sections of the BBC, however, are still not fully digitised and the competing digital systems used in news organisations can cause problems for cooperation between broadcasters. In Britain, ITN has the most integrated digital newsrooms across entire news organisations, with BBC and Sky News close behind.

In 1989, Spain's aspiring private broadcasters received the first licences permitting them to take to the national airwaves: Antena 3, Canal Plus and Telecinco entered the market with their own daily news broadcasts, ready to compete with the national public network TVE, but confronting a veteran newsgathering operation with worldwide reach and audiences longaccustomed to receiving their information from public broadcasters. But during the 1990s, audiences grew increasingly willing to get their news from private channels, and while TVE continues to deliver the most popular news programmes, both Telecinco and Antena 3 have seen their share of the audience rise sharply. Despite stiff competition from goverment subsidised networks, Telecinco became the second most profitable broadcaster in Europe in 1998.

Telecinco introduced digital technology with two basic objectives: to renovate a low-key news operation, based on outdated analogue equipment, and to gain both speed and costeffectiveness. The company invested $€ 12.5$ million in the construction of a new building that houses the studios for news programmes and a newsroom that holds 95 journalists. Using similar technology, Antena 3's digital newsroom was operationalised during 1999. One floor was completely renovated, to set up the new digital system, with over thirty editing terminals available to its 130 journalists. The cost of the operation for Antena 3 was $€ 6.25$ million.

Telemadrid was the first Spanish regional public television broadcaster to complete the digitisation of its newsroom, in January 2000. Telemadrid's management had considered implementing an integrated digital newsroom well before 1997, when the channel moved into a new building. In that year the company acquired digital equipment for most departments, except news, since they were thinking of installing an integrated digital newsroom. The cost of the whole operation was in the region of $€ 9$ million, which included 40 editing terminals for the 110 journalists and digitisation of the archive.

\section{Managing Change at the Workplace}

According to news managers, there was little internal resistance to the introduction of digital technology in the cases analysed in this study. Initially, some journalists stressed the drawbacks of their new status but, in the end, most of them welcomed the opportunity to have a greater control over the whole process and they were pleased with the final result. The new digital system was accepted by journalists as a tool that helps the job to be done more easily, rather than something that hinders their work or the quality of the news output.

At the BBC there was an initial reluctance 
among some journalists to adapt to the new systems, but this was largely overcome when journalists discovered the benefits of, for example, writing scripts to images they themselves selected and edited. In each news organisation there were broadcast journalists who welcomed the opportunity to retrain and to improve their range of skills, seeing this as an empowering and positive element in their careers.

In the Spanish case, most journalists thought the introduction of a digital newsroom offered an excellent opportunity to obtain greater control over the final product, since less dependence on technicians was required. As Telemadrid's news director explained:

Journalists were frightened when they first learned about the plans for the new system, but everything changed the day they started to get to know the machine and saw that it was, on the one hand, very simple to use and, on the other, great fun. Now, no one in the newsroom wants to return to the old system. Everyone is happy, because furthermore they do not have to depend on another person to produce their stories.

Telemadrid was the only broadcaster that had to deal with more hostile reactions to the implementation of the new system, which came mainly from trade unions. Most of the resistance came from tape editors, whose jobs would be made redundant by the new system, which permits journalists to edit stories themselves. Unlike in Spain, the trade unions were not mentioned as a factor in embracing or resisting the changes introduced by the British broadcasters.

At Antena 3 and Telecinco, news managers stated that they worked hard with technical directors to make joint decisions about which system would be most suitable to meet journalistic demands. From the start, this joint effort made it easier to win journalists' approval of the proposals made by the technical directors during the design stage. As Telecinco's technical manager put it:

As engineers we tend to develop technical structures and then pass them on to users. This time we did it the other way round: we worked with journalists to find out their needs, and then we looked for a system that would suit them and, at the same time, be user friendly. Journalists spend eight hours a day working on a computer, so they must feel comfortable with that.

The cooperation between the technical and journalistic areas was also highlighted by news directors at the BBC and ITN. Their joint work played a pivotal role in making decisions about sweeping changes in decades-old work systems and routines.

The notion of making the news operation more cost-efficient was also a key factor in implementing these new systems. However, as Antena 3's technical director said, "you need to explain the reasons for the change, and not to focus only on issues such as efficiency and money". In Britain too, senior news executives explained that the rationale for the introduction of digital technology was speed and costeffectiveness. Although at the BBC, one executive expressed scepticism about its short-term cost benefits:

I think it is a rare digital beast that saves you money. I think that by the time you have trained everybody it is a long-term investment. It is not something that is going to immediately show you a benefit in forms of saving money ... In a big operation like the BBC, you can never run out the whole thing in one go. You can't afford to throw everything away and bring in a new format. It is always going to be a sort of mixed economy. A lot of those costs are hidden; you never quite know what they are. Extra time spent dubbing things, extra time spent in people getting it wrong and having to re-do stuff.

Specifically addressing the economics issue, we found an age gap in both countries. Many of the reporters who are over 40 had lived within a rule-regulated, hierarchically ordered and technologically cautious work culture. For them an entirely new digital system was a source of added pressure on their status and job security. They were more likely to agree that news and staff budget cuts would be the consequence of the huge investment in new technology. On the contrary, younger journalists felt the changes would benefit their careers. They were not as conscious as older journalists of financial downsizing.

Training was regarded as "essential" in all newsrooms studied. Among the biggest challenges news directors faced was training journalists to adapt to the new tools and convincing 
them that technology was, in fact, going to make their lives easier. A common theme in the British newsrooms, however, was the gap between executive ambition and the reality of practice. The aim of training journalists to deal with most, if not all, of the production process did not work out as envisaged in some cases. One BBC reporter, speaking about the original managerial ambition, said that:

it hasn't gone as far as they originally hoped because the original idea was that we would be editing whole packages ourselves. They tried to send us on courses to learn that type of thing but it hasn't worked because it is too specific and there is still too much division.

Training often meant that journalists dedicated hours of extra time, with no financial compensation, to get acquainted with the new tools. Courses were mainly technically oriented, covering areas such as computer skills, use of digital servers, access to incoming digital material and production of news items.

A significant exception was found in the case of Telecinco, where training included visual grammar, picture editing and improved storytelling, with an emphasis on helping journalists to make decisions about when they would edit the stories themselves. In this newsroom, some of the stories in the news broadcasts were edited on computer-based, non-linear systems (although they were finally taped for transmission), so that journalists could get used to the new editing software three months before launching the digital system. Training programmes decreased the time reporters spent on technical matters and allowed them to devote more attention to news content. One of Antena 3's news directors also pointed out the need to lead the process of change from within so that journalists would find the experience worthwhile:

The most important thing is creating enthusiasm for change among your own journalists. Information is the basis for succeeding in this. At a very early stage we organised a number of seminars, internal meetings, with all the groups in the newsroom. This enabled us to address and answer all the questions they had about their concerns.

All three Spanish networks confronted several technical problems in the weeks following the launch of the new system. The digital network crashed several times and parts of the edited work were lost and could not be aired. Also some of the automated process had to be done manually. In Telemadrid the whole system collapsed just at the beginning of the evening newscast, which had to be postponed for twenty minutes. According to the technical director,

The system has a high level of risk, since all the materials are stored in the same server. In addition, the way we work does not allow us to make a backup of the packages, since most of them are edited at the last moment.

Some journalists wait until the "last minute" to finish their work, which means, according to the same source, that they "trust the system too much". Although all video packages edited within 15 minutes before air-time are taped, this is not of much help, since most packages are finished closer to air-time.

The BBC also encountered technical difficulties with 24-hour news. BBC News-24 was launched on 9 November 1997 and BBC News Online went online the same month. Almost immediately there were problems with the technology and the newsroom suffered several blackouts.

\section{Newsroom Workflow}

Generally speaking, digital technology has been adapted to the existing newsroom structures. Nevertheless, some new positions have been created. In Spain a number of significant changes have been made in the structure of the Telecinco and Antena 3 newsrooms. Two new jobs were created: system managers and media managers. System managers usually have an engineering background and they take care of the technological aspects of the equipment. Media managers take charge of the traffic of information inside the newsroom, they assign "profile lines" (access to the main server) to every reporter in order to edit the news items. Some responsibility for content decisions, although nominally resting with the programme editor, has been transferred in practice to the 
media manager. They also decide priorities in the allocation of resources.

Media managers are also advanced users of the system, since they have received more extensive training and are able to diagnose system failures. Four media managers usually work on the traffic desk on each shift, assigning the necessary system resources to the users. Once reporters edit their stories, they are sent back to the server from where they can go straight on air. A selection of the material will remain in the server for five days. Afterwards, it is available in a digital library.

At Telemadrid, however, there has not been any significant change in the structure of the newsroom or its workflow. Some new positions have been introduced in the traffic control room in order to direct and store news feeds from international agencies and from staff members working outside the central facilities. According to the technical manager, some of the new technical jobs involve little creativity and a great deal of responsibility.

In Britain, bucking the trend of job reduction, in each news organisation the new role of media manager has also been introduced. The media manager, explained a BBC journalist, "is responsible for house-keeping of the pictures ... These people are monitoring things coming into the building and are responsible for 'binning' things that aren't needed anymore." In the fully digitally integrated studios established for 24-hour news, the role of camera operator had disappeared altogether and been replaced by remote cameras operated from the output station.

Although no specific data were provided by management, it is certainly the case that job reductions have occurred in some British news organisations for reasons that those interviewed attributed to the introduction of digital technology. On the contrary, the Spanish newsrooms have not experienced any job reduction, for several reasons. Trade unions put pressure on managers from the outset to ensure that any redundant workers would be relocated; the new system provided an increased number of hours of news for those channels, and also the medium size of the newsrooms made it easier to assign new jobs within the company.
In Britain a number of respondents speculated that the original intention in introducing digital technology had been to remove the difference between the role of journalists and that of more technical roles such as the camera operator and the sound and tape editors. The new designations for journalists who combine journalistic and technical skills-“operational broadcast journalist" at the BBC and "production journalist" at ITN-in part express this ambition and its achievement. However, the real difficulties in acquiring all these skills and at the same time maintaining quality meant that the reduction in technical jobs had not gone as far as management might have wished.

News directors interviewed at all three Spanish networks emphasised that with the introduction of the system there was an accompanying decision not to change either programme content or programme design, but rather to improve the competitiveness of the networks. As Telecinco's news director argues,

We have increased our competence as news pro-
ducers. We need our staff to think of producing
news content, which could be distributed not only
through television but also on the internet and
radio. We must provide quality news but we must
also be there faster and faster. Our environment is
getting much more competitive. But we are striv-
ing to provide much more context about what's
happening: to be more analytical and explain to
our audience why those events occur. In this sense,
multiple access to all video material and the im-
mediate use of the digital library has enhanced our
capability to provide that context.

Some journalists in both Spanish and British newsrooms made the point that the new system does not change their job in a radical manner. In the words of an Antena 3 reporter, "digitisation is nothing more than a technical advance. It is an advance but the tools are just instruments ... In the end, no digitisation will substitute for the prime material, which is the journalistic quality of our editors."

The role of the programme and news editors was not seen to have changed radically. "They are still responsible", said one news executive, "for the output of their programme and the running orders; what goes in and what can be dropped." It was acknowledged, however, that 
the erosion of "the separation between the pictures and the journalism" meant they would be "more in charge of the actual pictures and how they were going out".

However, editorial control is an issue in a digital integrated newsroom, since the system is designed to allow management to control the content easily, and programme editors have immediate access to the pieces being worked on by each journalist.

The system allows editors to access reporters' pieces while they are still being produced at their editing terminals. Some of the news directors interviewed confirmed that they now can access every script and video once it is in the system ready to be broadcast, and that they can suggest last minute corrections or improvements. Editors also point out that some of the items are finished just before going on air, which means they sometimes are unable to supervise them.

In a digital environment, archiving can no longer be separated from all the other processes in the news production cycle, and the decision of what goes into the archive is becoming part of media management. All Spanish newsrooms have already implemented digital archive systems, whereas in Britain the picture is a little different. A technical lag compared with Spain was found with regard to archiving. No news organisation has yet digitised its archives and how to archive and what to archive are considered major challenges ahead.

At Telemadrid, Telecinco and Antena 3, the new digital library allows journalists to browse the key frames of a package, and to search for key words, with instant access to recent archive material. The digital system allows journalists to get closer to the material and to have greater control and decision-making power when editing each story.

Digitisation of the library has prompted some changes in the way the newsroom operates. First of all, the fact that library pictures can be accessed online makes it easier for journalists to include them as part of their stories. Secondly, production assistants do not have to go and find archive material as they used to do.
Finally, librarians now have a very important role in the newsroom, since they have to decide which material remains accessible on the server, and which is taken off.

\section{A Greater Role for Multi-skilling}

Although multi-skilling can be observed to some degree in all the networks analysed, the Spanish newsrooms have moved further in this direction, since their integrated digital newsrooms operate on the principle of a new role for journalists, who must now edit pictures on their personal computers. In Britain there are journalists who edit their own pictures but this is by no means the norm.

Traditionally, in most Spanish television newsrooms journalists were mainly concerned with editorial content: they had to gather background information, interview sources, write the text and read the voiceover. Technicians took care of editing the video. Although there were a few attempts to establish multi-skilling, with differing degrees of success, before the new digital equipment was introduced, journalists typically did not edit the stories themselves, although they usually had the final decision on the cut, which was made by tape editors in their presence.

Initially, multi-skilling seemed a difficult challenge for most journalists. But after a month working with the new system, the majority adapted well and reporters were much more involved in shoots out in the field because they knew they would have to edit the video later. Telecinco's manager of technical directors argues that journalists are now more interested in picture editing, since they know more about visual grammar. In addition, the fact that one person writes the text and edits the pictures allows for a better combination of pictures and words.

Telemadrid's news editor explained that multi-skilling allows for higher quality in the final result, since journalists have more creative and expressive tools: 
Much of the success of our news programmes depends on journalists working rapidly and accurately, and with total confidence in their own abilities and in the equipment. And they have learned to solve typical editing problems in a realistic time-frame. After a few weeks, they were much better in working with the visuals and making the most of their journalistic craft, in their job of telling and explaining the news.

Nevertheless, he warned against the use of multi-skilling exclusively for economic reasons, which could worsen the quality of the news output. The general view was that multiskilling is increasingly a necessary requisite for a journalist.

A number of British journalists also saw multi-skilling as a desirable development. One BBC Milbank journalist explained:

I think journalists who can do more than one task are desirable. There is a payback for journalists who can do things themselves because a journalist will be quicker to spot a picture which tells the story because he understands the story and there have been numerous occasions when I have shot stories because I knew instinctively the significance of that picture.

Another journalist explained that the new environment requires versatility, speed and accuracy: "The key to the job here is to be able to do as many things as possible as quickly as possible and as accurately as possible. Anything from writing scripts for presenters to read, to cutting pictures that go out on air, writing your own reports and putting your voice down on the report."

Some journalists also emphasised the problems with multi-skilling, highlighting the paradoxical tendency to place journalists in a narrower role in processing the news. At Telecinco and Antena 3, several reporters expressed their concern about becoming "content packagers", as one of them put it, devoted to repackaging agency feeds for different outlets. According to a BBC journalist, reporters have to work "ten times harder" and cannot go out on the stories as they used to because they have to service a live output of 24-hour news, as well as other radio and television outlets. Therefore it is quite rare for journalists to have the opportunity to go out and chase a story.

British journalists explained that there was a considerable emphasis on processing and, as one of them put it, "an element of write it down and whack it out", particularly working in 24hour news. The need for speed and the expectation that journalists should also possess editing skills caused some anxiety that quality might be compromised. Multi-skilling, explained one journalist,

has some drawbacks too which are particularly to do with people like me cutting headlines. We neither want to do it or spend too much time over it. In the past headlines would have been carefully cut, now we just try to grab 12 seconds and chuck out the best that you can. Whereas in the old days when you had an editor doing it, you may have 4 seconds of this and 5 seconds of this which fits with the words. That happens less now. Also what happens more is that you'll just get a headline or an OOV, an out of vision, with the news reader reading with some pictures over. There is no natural sound because usually you've just grabbed it out of the package where in theory you should spend a long time stripping the sound off.

A BBC executive summed up the difficulties of comprehensive multi-skilling:

There is a kind of crossover in the middle of shared skills. But I don't think I know of anybody working in the broadcast market, in BBC news services who would be able to do every single aspect of getting it on air. It is too big, it is too complex an operation and that person by being a Jack of all trades would not be a master of any of them and they don't need to be. You need some commonality between some areas and where the boundaries are blurred that is a good and efficient use of people time. But to have someone who works across the whole field, that is too much for any one person to do.

Some of the issues raised by multi-skilling in both Britain and Spain were expressed well by a BBC executive. In his view, multi-skilling may not be readily accepted by some journalists whose real skills are not related to the technical side but to thinking and writing. In addition, if 
all journalists became multi-functional, there is a danger of "grey uniformity in the broadcast industry if everybody had the same skills, since you need people who can edit their stuff ... and also some creative imaginative broadcasters in front of the camera, who have interesting ideas to put out".

\section{Journalists' Relationship to Time}

Technological developments-such as the digital newsroom, the portable satellite dish, digital satellite telephone, the portable digital editing suite-have helped to speed up the gathering, processing and editing of news, while also allowing journalists to reprocess and repackage news. In the words of an ITN journalist, "The key thing is to have fresh news as quickly as possible and the emphasis is on doing things really quickly." On the one hand, such developments seem to enhance the journalistic function, making it more efficient, and, on the other, they raise concerns about the quality of the content produced and the impact of the changing nature of news production on journalists' ability to retain their professional values. This was reflected in one BBC journalist's comments:

People can spend the day in that newsroom and not write a word really because they'll be marking ins and outs and dubbing things. In fact, I know from the latest board [BBC selection board] that they had, that one of their biggest criticisms of the candidates was that although they were all very competent with digital technology, they had a writing test which they weren't so good at and that probably is partly because they don't spend as much time writing any more. Also, partly because people don't pay so much attention, everyone is worried about where the pictures are coming from and who is cutting what and so on that no one really pays as much attention to the script as they used to.

Integrated digital newsrooms make it possible to finish stories closer to air-time, since changes can be introduced more easily. In all the Spanish digital newsrooms, the number of editing terminals was at least doubled, and journalists now do not rely just on a few editing booths, where bottlenecks might have occurred shortly before broadcast time. However, according to Spanish programme editors, in some cases the whole process from input to air for each story takes approximately the same time it took with the analogue system. Editors mentioned two reasons that would explain this: journalists now dedicate more time to polishing the final cut and sometimes they have to wait until incoming tape material is digitised.

However, one reporter at Antena 3 argued that the system provides some independence, which can help to improve the content: "With the analogue system, you wasted more time waiting for your item to be edited in the booths. Now you can organise your time according to your own deadline."

Since reporters now spend more time editing their own packages, working with the visual material and using their computers, presumably they have less time available for gathering background information and planning and producing their stories. Telemadrid's technical manager supported this view:

The digital system allows producers to allocate editing resources to newsroom demands, to track the progress of editing and ensure that all items for transmission are complete and ready in good time. With the analogue videotape system, the process was slower and edits could not be done as easily as with the computer.

In Britain, news executives shared the view that key qualities for a journalist in the digital age were to be organised and to have great stamina, the latter being especially necessary for those working within a 24-hour news environment. The relentless pressure of time was experienced not only in the speed that was required to produce news, but also in the great stretches of time which, in 24-hour news environments, had to be filled. Digital technology, in the words of one ITN journalist, allows "less and less excuse for delay". Going straight to a story as it breaks is the goal of news organisations.

Certainly journalists and news executives noted that the use of live two-ways had become an important part of the news vocabulary. One BBC journalist attributed what he considered to be their increased use to the larger market for news and the availability and price of satellites. The trend to use more live two-ways was not always considered a welcome development. 
There is a tendency to do two-ways with people before they fully know the story and this is a potential source of problems. One journalist explained his frustration at constant demands for live two-ways for different news outlets: "For God's sake, I'd like to go out and get the blasted story. It is like that everywhere. The pictures have come in, we expect a package on that in half an hour's time. There isn't quite the time to consider it."

However, the increase in the liveness of television news was judged by one British executive to be less a consequence of digital technology than about "air-time and the availability and price of satellites". She explained that "we go to live events all the time... May be too much, but it is there now where it wasn't five or six years ago. So that is not part of the digital issue, it is all part of the same culture of continuous news."

\section{Conclusion}

This article has identified differences in the work of journalists at public and commercial broadcasters in both Spain and Britain, after several years of digitisation of their newsroom operations. An investigation of journalists' perceptions of their practice in a rapidly changing environment must take into account the negative and positive effects of the digital systems and the ways in which journalists have appropriated technology to improve elements of their activity.

We have seen how television journalists adapt to the constraints and pressures placed on them by technological developments, financial constraints and reduced numbers of staff. Despite these increasing pressures, the existence of a specific journalistic culture ensures that a set of shared practices and values continues to exist in newsrooms. A shared belonging to a journalistic culture means that there is general acceptance that the new skills and practices necessary for using new technology can improve and make newsgathering and processing more efficient. Although certain core journalistic values such as accuracy and the ability to go out on a story need to remain constant, there is concern that these are being threatened by new working practices. However, despite the fact that some journalists displayed concern about the changing nature of their job, particularly the sense of being short of time and becoming too technically oriented, there appeared to be little dissent about the introduction of new technology expressed in newsrooms.

There are differences in size, culture, structure and output between the six channels analysed here and consequently comparisons must be drawn carefully. In general, the reason for introducing a digital system was the attempt to improve cost-effectiveness, which has been partially achieved. In some cases, the implementation of digital technology was seen as an opportunity to reshape the newsroom size and structure. Significantly, in some British newsrooms, the new technology is seen as the cause for job reductions (particularly at ITN), whereas in Spain there have been no job losses in any of the newsrooms studied. Workflow within the newsrooms has changed moderately and this has resulted in the creation of the new position of media manager in most newsrooms.

The relatively smaller and younger Spanish newsrooms have introduced wide structural changes such as allowing journalists to edit the packages, while British newsrooms display greater inertia and have tended to incorporate the new tools within the previous newsroom structure. New positions have been created in five of the six newsrooms as a consequence of the requirements of the new technology. In other cases, old positions have acquired new roles, especially in the Spanish newsrooms, where the archive is already digitised and librarians fulfil a more important role in the research process.

In every case there was initial resistance to change but, after completion, there was a general acceptance that the advantages of the digital systems outweigh possible disadvantages. At times news workers have placed too much trust in the system, since technical failures occurred in some newsrooms, particularly in the first weeks of operation. It would seem that technology must reach a greater degree of reliability if it is to match the expectations of news workers. 
In the digital age, journalists increasingly work in multimedia companies, and they face a greater demand for multi-skilling in their work. Although it has been a matter for concern among news workers, multi-skilling seems to be a trend that will increase in the near future mainly because of economic reasons. Nevertheless, the possible negative effects of this trend make it necessary for companies to adopt the model carefully to avoid endangering traditional journalistic skills and to ensure that a diversity of expertise is retained in the newsroom.

Digitisation seems to have an ambivalent impact on journalism. Multi-skilling leaves journalists less time to fulfil traditional journalistic practices, such as double-checking of sources and finding contextual information. The newly established routines tend to emphasise the importance of speed, which sometimes raises concern about the quality of the output. In addition, the fact that technology allows for faster processing of news increases the pressure to be first with the story and to provide more on-the-spot, instantaneous live news, which leaves very little chance to explain context. This is particularly so in the case of 24-hour news channels, where journalists must report live on events that they have very little time to research. On the other hand, digital archives make it easier to use file material, which can allow journalists to contextualise their stories more fully. The routines of digital production seem to have an impact on structuring news. However, the effect of changing journalistic practice on news output requires further research.

The situation unfolding in Britain and Spain provides the ideal backdrop for conducting future research as significant changes in market structure, outlets (cable, satellite and the internet) and performance take place. On the basis of this discussion, it would seem that further comparative news research, oriented to the production domain and the ways in which digitalisation may be influencing the quality of news output, might prove valuable.

\section{Note}

1 In Britain data were gathered from observations and interviews conducted in the newsrooms of three British television stations: the BBC, ITN and Sky News. The BBC is a public service broadcaster funded by a licence fee. Independent Television News and Sky News are both commercial news organisations. In Spain, data were also gathered by observations conducted in the newsrooms of the three Spanish television stations: Telecinco, Antena 3 and Telemadrid. Both Telecinco and Antena 3 are commercial broadcasters funded by advertising. Telemadrid is a regional public service broadcaster, funded both by advertising and by financial aid from the Regional Government of the Community of Madrid.Semi-structured interviews were conducted with 13 senior managers and journalists from BBC, ITN and Sky News newsrooms in Britain and 11 from Telecinco, Antena 3 and Telemadrid (see Appendix for details of those interviewed). All the journalists interviewed were helpful and willing to answer follow-up questions. During the period of observation, it was important that journalists working in the newsroom and the researchers became used to each other, in order to create an unobtrusive relationship. The observation notes were mainly concerned with descriptions of the work of journalists in the various stages of news production, the use of digital technology and the organisational structure of the newsroom. The information gathered in these periods of observation, which extended over two days in each newsroom, was then used for preparing the open-ended interviews with journalists. A similar interview schedule was used in each country and was refined and modified to take into account new, related questions as the research progressed. Through literature study, discussions with experts and observation, three different kinds of open-ended interviews were prepared, one for each professional level: news directors, system users and technical directors.

\section{References}

Bandrés, Elena, García Avilés, Jose Alberto, Pérez, Gabriel and Pérez, Javier (2000) El periodismo en la televisión digital, Barcelona: Paidós.

BBC (2002) A Review of BBC News, London, < http://www.bbc.co.uk>.

Blumler, Jay G. and Gurevitch, Michael (1995) The Crisis of Public Communication, London: Routledge.

Blumler, Jay G., McLeod, J. and Rosengren, Karl E. (Eds) (1992). Comparatively Speaking: communication and culture across space and time, Newbury Park, CA: Sage.

Bromley, Michael (1997) "The End of journalism? Changes in workplace practices in the press and broadcasting in the 1990s", in: Michael Bromley and Tom O'Malley (Eds), A Journalism Reader, London: Routledge, pp. 330-50.

Byrne, Ciar (2002) "ITV Journalists Braced for Cuts", 12 July, <www.mediaguardian.co.uk $>$.

Cottle, Simon (1993) TV News, Urban Conflict and the Inner City, Leicester: Leicester University Press. 
Cottle, Simon (1995) “The Production of News Formats: determinants of mediated public contestation", Media, Culture and Society 17, pp. 275-91.

Cottle, Simon (1999) "From BBC Newsroom to BBC Newscentre: on changing technology and journalist practices", Convergence 5(3), pp. 22-43.

García Avilés, José Alberto and León, Bienvenido (2002) “Journalistic Practice in Digital Television Newsrooms: the case of Spain's Telecinco and Antena 3", Journalism: Theory, Practice \& Criticism 3(3), pp. 355-71.

Hardt, Hanno (1990) "Newsmakers, Technology and Journalism History", Critical Studies in Mass Communication, 7, pp. 346-65.

Harrison, Jackie (2000) Terrestrial Television News in Britain: the culture of production, Manchester: Manchester University Press.

Hodgson, Jessica (2002) "ITN News Channel Losing £3/4m a Month", 12 July, < www.mediaguardian.co.uk>.

MacGregor, Brent (1997) Live, Direct and Biased? Making television news in the satellite age, London: Arnold.

Marjoribanks, Timothy (2000) News Corporation, Technology and the Workplace: global strategies, local change, Cambridge: Cambridge University Press.

Pavlik, John (1999) “New Media and News: implications for the future of journalism", New Media and Society 1(3), pp. 54-59.

Peters, John Durham (2001) "Witnessing", Media, Culture and Society 23(6), pp. 707-23.

Sanders, Karen and Bale, Tim (2000) "The Symbolic Agenda of a British Satellite Broadcaster's 1997 Election Coverage", Journal of Electronic and Broadcast Media 44(3), pp. 487-502.

Schudson, Michael (1995) The Power of News, Cambridge, MA: Harvard University Press.

Schudson, Michael (2000) "The Sociology of News Production Revisited (Again)", in: James Curran and Michael Gurevitch (Eds), Mass Media and Society, London: Arnold, pp. 175-200.

Schlesinger, Philip (1987) Putting Reality Together, London: Methuen.

Tusa, John (1994) "Programme or Products: the management ethos and creative values”, James Cameron Memorial Lecture, 14 June, City University, London.

Ursell, Gillian (2001) "Dumbing down or Shaping up? News technologies, new media, new journalism", Journalism: Theory, Practice \& Criticism 2(2), pp. 175-96.

Ursell, Gillian (2003) "Creating Value and Valuing Creation in Contemporary UK Television: or 'dumbing down' the workforce”, Journalism Studies 4(4), pp. 31-46.

Winston, Brian (1998) Media, Technology and Society, London: Routledge.

\section{Appendix. List of Interviewees}

\section{Spain}

José Luis Romero, Telecinco's technical manager, 19 October 2001.

Cristina de la Vega, head of Telecinco's digital library, 19 October 2001.

José Luis Fuentecilla, Telecinco's reporter, 21 June 2000.

Manuel Rodríguez, Telecinco's manager of technical directors, 20 June 2000.

Vicente Vallés, assistant news director, Telecinco, 19 October 2001.

Juan Pedro Valentín, news director, Telecinco, 19 October 2001.

Jesús Martínez, technical manager, Antena 3, 27 March 2000.

Ernesto Sáenz de Buruaga, news director, Antena 3, 27 March 2000.

Nekane Goñi, reporter, Antena 3, 27 March 2000.

Daniel Iribar, Telemadrid's news editor, 18 October 2001.

José Luis Alcalá, Telemadrid's technical manager, 18 October 2001.

\section{Britain}

Nigel Dacre, ITN, 28 January 2002.

Adam Chadwick, ITN, 28 January 2002.

Jane Thompson, director, ITN, 28 January 2002.

Richard Zackheim, production journalist, ITN, 28 January 2002.

Peter Taylor, operations manager, BBC Milbank, 27 July 2000.

Gerry McGoldrick, director, BBC World, 26 July 2000.

Mark Mitchell, assistant editor technology and training, BBC, 26 July 2000.

Richard Porter, senior editor, BBC News 24, 26 July 2000.

Simon Cole, managing editor and deputy head of news, Sky News, 28 July 2000.

John Ryley, executive editor, Sky News, 28 July 2000.

Paul Vickerage, head of technical operations, Sky News, 28 July 2000.

Stephen Benedict, Sky News, 28 July 2000. 